Yüzüncü Yil Üniversitesi
Tarim Bilimleri Dergisi

Araştırma Makalesi (Research Article)

\title{
Bazı Allium Türlerinin Morfolojik Ölçümleri, Stoma ve Polen Özellikleri ile Polen Canlılığının Belirlenmesi
}

\section{Ezelhan ŞELEM $^{1 *}$, Lütfi NOHUTÇU² ${ }^{2}$, Rüveyde TUNÇTÜRK ${ }^{3}$, Murat TUNÇTÜRK ${ }^{4}$}

1,2,3,4Van Yüzüncü Y1l Üniversitesi, Ziraat Fakültesi, Tarla Bitkileri Bölümü, 65090, Van, Türkiye

${ }^{1}$ https://orcid.org/0000-0003-4227-5013 ${ }^{2}$ https://orcid.org/0000-0003-2250-2645 ${ }^{3}$ https://orcid.org/0000-0002-3759-8232

${ }^{4}$ https://orcid.org/0000-0002-7995-0599

*Sorumlu yazar e-posta: ezelhanselem@hotmail.com

\section{Makale Bilgileri}

Geliș: 08.09.2020

Kabul: 20.10.2020

Online Yayınlanma 31.12.2020

DOI: 10.29133/yyutbd.791621

\section{Anahtar kelimeler}

Allium,

Adaptasyon,

Polen,

Stoma.
Öz: Allium türleri çok çeşitli alanlarda kullanılmasına karşın Doğu Anadolu Bölgesi'nde baharat, kan şekerini düzenleyici, bağırsak sorunlarını giderici, ağrı kesici, yara iyileştirici, akne tedavisi ile otlu peynir yapımında kuru veya yaş olarak sıkça tercih edilmektedir. Bu çalışmada ülkemizde özellikle aroması ve antimikrobiyal özelliğinden kaynaklı yoğun olarak kullanılan bazı Allium türlerinin morfolojik ölçümleri (bitki boyu, sap boyu ve çapı, yaprak boyu ve çap1, yaprak sayısı, umbella çapı, pedisel uzunluğu), stoma ve polen özellikleri ile polen canlılığının belirlenmesi amaçlanmıştır. 2016 yılında Van ve çevresinde yapılan arazi gezmeleri sırasında doğal ortamlarından toplanan Allium akaka, A. giganteum, A. kharputense, A. scorodoprasum subsp. rotundum, A.vineale ve $A$. sintensii türleri Van Yüzüncü Yıl Üniversitesi Tıbbi Bitkiler Bahçesi’nde hazırlanan parsellere ekilmiş ve kültüre alınmıştır. Sonuç olarak, bitkilerin bulunduğu gözlem parsellerinde yapılan ölçüm ve değerlendirmelere göre morfolojik özellikler bakımından iyi bir adaptasyonun olduğu görülmüş, $A$. kharputense ve $A$. sintensii türlerinin diğerlerine kıyasla daha zayıf bir gelişim gösterdiği belirlenmiştir. Yüksek tohum veriminde önemli bir parametre olan polen miktarı ve canlılık oranlarında ise A.vineale ve A. scorodoprasum subsp. rotundum türlerinin ön plana çıktığ 1 görülmüştür. Adaptasyon ve fotosentezde önemli bir rolü olan stomaların yoğunluğu en fazla $A$. kharputense türünde olup, en yüksek ölçülere ise $A$. vineale türünün sahip olduğu görülmüştür.

\section{Determination of Morphological Measurements, Stoma and Pollen Characteristics with Pollen Viability of Some Allium Species}

\section{Article Info}

Received: 08.09.2020

Accepted: 20.10.2020

Online Published 31.12.2020

DOI: 10.29133/yyutbd.791621

Keywords

Allium, Adaptation,

Pollen,

Stomata.
Abstract: Although Allium species are used in a wide variety of fields, they are frequently preferred as dry or fresh spices for intestine disorders, loss of appetite, for regulating blood sugar, pain reliever, wound healing, acne treatment and herby cheese making in the Eastern Anatolia region. In this study, it was aimed to determine of morphological measurements (plant length, stem length and diameter, leaf length and diameter, number of leaves, umbella diameter, pedicel length), stoma and pollen characteristics and pollen viability of some Allium species which are used extensively in our country especially due to their aroma and antimicrobial properties. Allium akaka, A. giganteum, A. kharputense, A. scorodoprasum subsp rotundum, A.vineale and $A$. sintensii species collected from their natural habitat they were cultivated and planted in plots prepared in the Van Yüzüncü Yıl University Medicinal and Aromatic Plants Garden during the field 
trips from Van and surrounding cities in 2016. As a result, according to the measurements and evaluations made in the observation plots where the plants are located, it has been observed that there is a good adaptation in terms of morphological features, it was determined that $A$. kharputense and A. sintensii species showed a weaker growth than others. In terms of pollen amount and vitality, which is an important parameter in high seed yield, it was observed that A.vineale and $A$. scorodoprasum subsp. rotundum species came to the fore. It has been observed that stomata, which play an important role in adaptation and photosynthesis, have the highest density of $A$. kharputense species and the highest measure is $A$. vineale.

\section{Giriş}

Allium cinsi soğanlı bitkiler, Amaryllidaceae familyasında 600 'den fazla tür ile temsil edilmekte olup, ülkemizde 72 tanesi endemik olmak üzere toplam 180 türe sahiptir (Kaya, 2014). Organosülfür bileşikleri ve polifenoller gibi biyoaktif bileşiklerce zengin olduğu bilinen Allium türleri antioksidan, antifungal, antimikrobiyal, antiviral, antimutajenik, antidiyabetik ve prebiyotik gibi özellikler göstermektedirler (Rosello-Soto ve ark., 2018; Putnic ve ark., 2019). Ayrıca antitrombotik, antihipertansif, hipolipidemik, hipokolesterolemik ve anti-hiperhomosisteinik etkileri nedeniyle kardiyovasküler hastalık riskini azaltmaya da yardımcı oldukları bilinmektedirler (Saljoughian ve ark., 2017). Tür sayısı bakımından çeşitlilik gösteren Allium cinsinin diğer türleri, yörelere göre farklı amaçlarla kullanılmak üzere doğadan toplanmaktadır. Yaprak, sürgün ve soğanları tüketilen Allium türleri Anadolu’da 'kurad', 'sirmo', 'sirim', 'sirik', 'körmen', 'soryaz', 'handuk', 'luş', 'çorin’ gibi yöresel olarak adlandırılmaktadır. Allium türleri gıda olarak tüketimlerinin yanı sıra süs bitkisi, yara iyileştirici, ağrı kesici, kan şekerini düzenleyici, kolesterol düşürücü olarak da kullanılmaktadırlar (Ekşi ve ark., 2020; Tunçtürk ve Tunçtürk, 2020). Van Gölü Havzası'nda ise birçok Allium türü daha çok otlu peynir yapımında kullanılmakta olup, son yıllarda yoğun toplamaya maruz kalarak doğadaki sürdürülebilirliği riske girmiştir.

Allium türlerinde yapılan çalı̧̧malar Allium cepa (soğan), Allium porrum (pırasa), Allium sativum (sarımsak), Allium schoenoprasum (frenk soğanı) ve Allium ascalonicum (arpacık soğanı) üzerinde yoğunlaşmıştır (Poojary ve ark., 2017). Allium cinsi çok sayıda türe sahip olmasına karşın ticari olarak belirli türlerin kültürü yapılırken birçok türleri de doğadan bilinçsizce toplanmaktadır. Dolayısıyla yapılan bilinçsiz toplamanın önüne geçmek açısından türlerin kültürünün yapılması önem taşımaktadır. Yapılan bu çalışma ile doğal ortamlarından alınarak yetiştirme parsellerine dikilen soğanların adaptasyon yeteneğinin belirlenmesi ve yapılacak diğer çalışmalara hem materyal sağlanması hem de kısıtlı olan literatürü zenginleştirmesi amaçlanmıştır.

\section{Materyal ve Yöntem}

Çalışma materyalini Van Yüzüncü Yıl Üniversitesi, Ziraat Fakültesi, Tarla Bitkileri Bölümü’ne ait geofit bahçesinde yetiştirilen altı Allium türü oluşturmaktadır. Çalışma materyalini oluşturan bitkilerin yetiştirme parsellerindeki görselleri Şekil 1.'de gösterilmiştir. 2016 yılında Van Gölü Havzası'nda yapılan arazi çalışmaları sırasında doğal ortamlarından toplanan Allium türleri Fen Fakültesi Biyoloji Bölümü'nde ilgili literatür doğrultusunda teşhis edilmiş olup VANF herbaryumlarındaki örnekler ile karşıllaştırılmıştır. Tür düzeyinde teşhisleri yapılan bitkilere ait soğanlar sonbaharda dikilmek üzere geofit bahçesine aktarılmış, adaptasyon yeteneğinin belirlenmesi amacıyla yetiştirilmiştir. $2 \mathrm{~m}^{2}$ lik parsellerde yetiştirilen türlerden kenar tesiri çıkarılarak rastgele seçilen 10 bitki üzerinde gerekli gözlem ve ölçümler yapılmıştır. Çalışmada kullanılan türler; Allium akaka, A. giganteum, A. kharputense, A. scorodoprasum subsp. rotundum, A. vineale ve A. sintensii'dir.

\subsection{Morfolojik ölçümler}

Morfolojik ölçümler geofit bahçesinde yetiştirilen bitkilerde 10 tekerrürlü olarak dijital kumpas yardımı ile yapılmıştır. Bitki boyu, sap boyu ve çapı, yaprak boyu ve çapı, yaprak sayısı, umbella çapı ve pedisel boyu ölçülmüştür. 


\subsection{Stoma ölçümleri}

Bitkilerden alınan yaprak örnekleri stoma analizleri için Tarla Bitkileri Bölümü’ne ait Fizyoloji ve Sitoloji Laboratuvarları'na taşınmıştır. Polen ve stoma ölçümlerinde Leica DM500 1ş1k mikroskobu, mikroskoba bağlı Leica ICC50 HD kamera ile Leica LAS EZ (versiyon 3.0) yazılımı kullanılmıştır. Stoma yoğunluklarını belirlemek amacıyla bitkinin 2. yapraklarının alt kısmına tırnak cilası sürülmüş ve kuruduktan sonra alınıp lam üzerine konularak mikroskopta incelenmiştir. Alana düşen stoma sayısı $\mathrm{mm}^{2}$ lik alana düşen sayı olarak belirlenmiştir.

\subsection{Polen canlılığı}

Açmak üzere olan çiçekler, polen canlılık testlerinin yapılması için Tarla Bitkileri Bölümü’ne ait Fizyoloji ve Sitoloji Laboratuvarları'na getirilmiş̧ir. Anterler, cam şişelerde güneş alan bir ortamda 24 saat bekletildikten sonra üzerine $10 \mathrm{ml}$ damıtık su ilave edilip homojenliği sağlamak amaciyla eser miktarda da deterjan eklenip karıştırılmışıtır (Eti, 1990). Karışım 1 saat bekletildikten sonra polen sayımı yapılmıştır. Canlılık testinde IKI testi (iyotlu potasyum iyodür) uygulanmıştır. Çözelti $100 \mathrm{ml}$ saf suda $1 \mathrm{~g}$ potasyum iyodür (IKI) ve $0.5 \mathrm{~g}$ iyot (I) eritilerek hazırlanmıştır. Mikroskopta koyu kahverengine sahip polenler canlı açık ve renksiz görünenler ise cansız olarak kabul edilmiştir. (Eti, 1990).

\section{4. İstatistik analiz}

$\mathrm{Bu}$ çalışma sonucunda elde edilen veriler, Tesadüf Parselleri Deneme Deseni' ne göre 3 tekerrürlü her tekerrürde 3 bitki olacak şekilde varyans analizine tabi tutulmuştur. Elde edilen varyans analizi sonuçları $\mathrm{F}$ testine göre değerlendirilmiş ve önemli çıkan uygulamalar LSD çoklu karşılaştırma testine göre karşılaştırılmıştır (IBM SPSS 22.0).

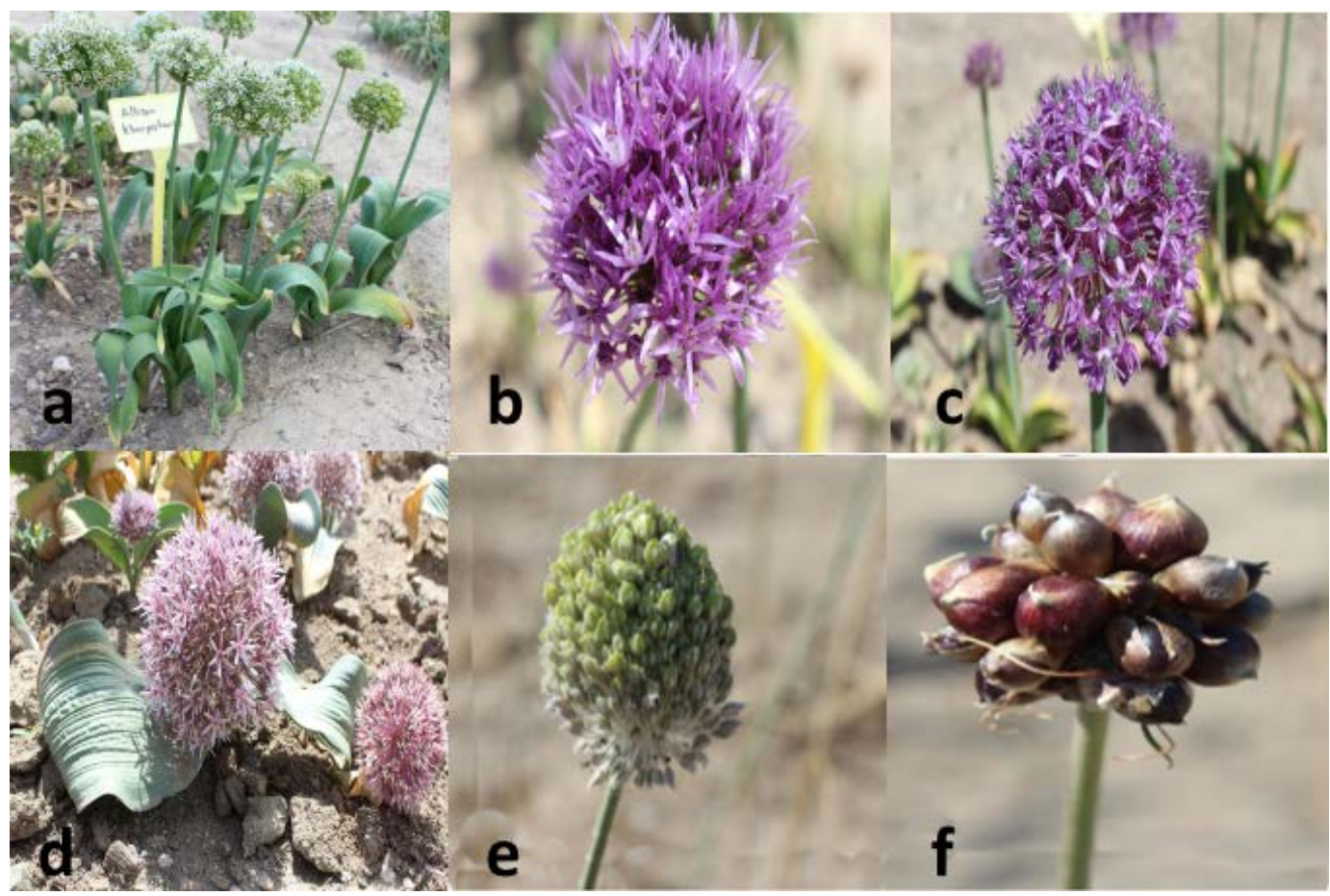

Şekil 1. Van YYÜ geofit bahçesinde yetiştirilen Allium türleri a. A. kharputense, b. A. sintensii, c. A. giganteum, d. A. akaka, e. A.vineale, f. A. scorodoprasum subsp. Rotundum. 


\section{Bulgular}

\subsection{Morfolojik ölçümler}

Çalışmada Allium türlerine ait incelenen tüm özellikler bakımından türler arasında istatistiksel olarak $\mathrm{P}<0.05$ seviyesinde önemli farklılıkların olduğu Çizelge 1 ve 2 'de görülmektedir. Yapılan ölçümlerde en yüksek bitki boyu $(78.8 \mathrm{~cm})$ A. scorodoprasum subsp. rotundum türünden elde edilirken, A. giganteum ve $A$. vineale türleri ile aralarında istatistiksel olarak bir farklılığın olmadığ ve aynı grup içerisinde yer aldıkları görülmektedir (Çizelge 1). En yüksek sap uzunluğu $(75.0 \mathrm{~cm})$ A. scorodoprasum subsp. rotundum türünde tespit edilirken, $A$. vineale türü ile aynı grup içerisinde yer almaktadır. Çalışmada en düşük bitki boyu $(14.2 \mathrm{~cm})$ ve sap uzunluğu $(5.80 \mathrm{~cm})$ A. akaka türünden tespit edilmiştir. Sap çapı bakımından en yüksek değer $12.2 \mathrm{~mm}$ olarak $A$. giganteum türünden ölçülmüş olup aralarında A. akaka türü ile istatistiksel olarak farklılığın olmadığı ve bu türlerin bu özellikleri bakımından aynı grup içerisinde yer aldığı görülmektedir (Çizelge 1). En düşük sap çapı değeri ise $3.85 \mathrm{~cm}$ ile A. vineale türünden belirlenmiştir. Yaprak boyu değerleri bakımından en yüksek değeri $(25.0 \mathrm{~cm})$ ile $A$. vineale türünden, en düşük değer ise $(15.6 \mathrm{~cm})$ ile $A$. giganteum türünde belirlenirken, $A$. vineale dişındaki diğer tüm türler aynı grup içerisinde yer almıştır. Çalışmada en yüksek yaprak eni değeri $(6.96 \mathrm{~cm}) A$. akaka türünden, en düşük değer $(0.54 \mathrm{~cm})$ ise $A$. vineale türünden elde edilmiştir. En fazla yaprak sayıs1 6.80 adet ile $A$. scorodoprasum subsp. rotundum türünden, en az yaprak sayıs1 ise 2.40 adet ile $A$. akaka türünden belirlenmiştir.

Umbella çapı ve pedisel uzunluğu bakımından en yüksek değerler sırasıyla $95.4 \mathrm{~mm}$ ve 33.2 mm olarak A. akaka türünde belirlenmiş olup her iki parametre için de A. akaka ve A. giganteum türü ile aralarında istatistiksel olarak farklılığın olmadığı, aynı grup içerisinde yer aldığı Çizelge 1'de izlenebilmektedir. Bu parametrelere ait en düşük değerler ise sırasıyla; $25.2 \mathrm{~mm}$ ve $12.5 \mathrm{~mm}$ olarak $A$. vineale türünde ölçülmüştür.

Yapılan çalışmada ölçülen parametrelere bakılarak türlerin adaptasyon yetenekleri gözlemlenmiş, literatür kıyaslamalarında $A$. kharputense türünün daha düşük bir gelişim gösterdiği ve yapılacak kültürel uygulamalar ile adaptasyonunun geliştirilebileceği düşünülmektedir.

Çizelge 1. Bazı Allium türlerinin morfolojik ölçüm ortalama değerleri ve oluşan gruplar

\begin{tabular}{lllllllll}
\hline Çeşit ad1 & $\begin{array}{l}\text { Bitki } \\
\text { boyu } \\
(\mathrm{cm})\end{array}$ & $\begin{array}{l}\text { Sap } \\
\text { uzun. } \\
(\mathrm{cm})\end{array}$ & $\begin{array}{l}\text { Sap } \\
\text { çap1 } \\
(\mathrm{mm})\end{array}$ & $\begin{array}{l}\text { Yaprak boyu } \\
(\mathrm{cm})\end{array}$ & $\begin{array}{l}\text { Yaprak } \\
\text { çap1(cm) }\end{array}$ & $\begin{array}{l}\text { Yaprak } \\
\text { say1s1 } \\
\text { (adet) }\end{array}$ & $\begin{array}{l}\text { Umbella } \\
\text { çap1 } \\
(\mathrm{mm})\end{array}$ & $\begin{array}{l}\text { Pedisel } \\
\text { boyu } \\
(\mathrm{mm})\end{array}$ \\
\hline A. kharputense & $38.8 \mathrm{c}$ & $28.4 \mathrm{~d}$ & $6.21 \mathrm{~b}$ & $19.0 \mathrm{~b}$ & $2.88 \mathrm{~b}$ & $5.20 \mathrm{~d}$ & $58.3 \mathrm{~b}$ & $26.3 \mathrm{ab}$ \\
\hline A. sintensii & $50.6 \mathrm{~b}$ & $42.6 \mathrm{c}$ & $4.87 \mathrm{bc}$ & $18.8 \mathrm{~b}$ & $2.36 \mathrm{bc}$ & $4.60 \mathrm{~d}$ & $52.0 \mathrm{bc}$ & $21.7 \mathrm{~b}$ \\
\hline A. giganteum & $69.8 \mathrm{a}$ & $58.1 \mathrm{~b}$ & $12.2 \mathrm{a}$ & $15.96 \mathrm{~b}$ & $1.00 \mathrm{~d}$ & $5.20 \mathrm{~b}$ & $90.5 \mathrm{a}$ & $33.1 \mathrm{a}$ \\
\hline A. akaka & $14.2 \mathrm{~d}$ & $5.80 \mathrm{e}$ & $11.8 \mathrm{a}$ & $16.0 \mathrm{~b}$ & $6.96 \mathrm{a}$ & $2.40 \mathrm{~d}$ & $95.4 \mathrm{a}$ & $33.2 \mathrm{a}$ \\
\hline A. vineale & $73.3 \mathrm{a}$ & $70.8 \mathrm{a}$ & $3.85 \mathrm{c}$ & $25.0 \mathrm{a}$ & $0.54 \mathrm{~d}$ & $3.60 \mathrm{c}$ & $25.2 \mathrm{~d}$ & $12.5 \mathrm{c}$ \\
\hline A. scorodoprasum \\
subsp. rotundum & $78.8 \mathrm{a}$ & $75.0 \mathrm{a}$ & $5.90 \mathrm{~b}$ & $20.4 \mathrm{~b}$ & $1.54 \mathrm{~cd}$ & $6.80 \mathrm{a}$ & $47.5 \mathrm{c}$ & $16.0 \mathrm{c}$ \\
\hline Ortalama & & & & & & & & \\
\hline F değeri & 54.3 & 46.8 & 7.47 & 19.2 & 2.54 & 4.63 & 61.3 & 23.7 \\
LSD & $69.41^{* *}$ & $94.27^{* *}$ & $86.97^{* *}$ & $8.69^{* *}$ & $139.68^{* *}$ & $34.18^{* *}$ & $107.38^{* *}$ & $19.32^{* *}$ \\
CV (\%) & 8.67 & 7.99 & 1.13 & 3.34 & 0.57 & 0.75 & 7.57 & 5.87 \\
\hline
\end{tabular}

${ }^{* *} \mathrm{p}<0.01$.

\subsection{Stoma ve polen morfolojisi ile polen canlılık durumu}

Yapılan çalışmada Allium türlerinde stomaların yaprakların alt yüzeyinde yoğunlaştığı görülmüştür. Geofitlerde iyi bir adaptasyonun sağlanması için bitki su dengesinin korunması önem taşımakta olup stoma yoğunluğu ve sayısı bu hususta ön plana çıkmaktadır. Stoma eni bakımından en yüksek değer $43.3 \mu \mathrm{m}$ ile $A$. vineale türünden tespit edilirken, en düşük değer ise $18.5 \mu \mathrm{m}$ ile $A$. kharputense türünden tespit edilmiş olup A. sintensii, A. giganteum ve A. akaka türleri ile aynı grup içerisinde yer almıştır. En yüksek stoma boyu $(51.6 \mu \mathrm{m}) A$. vineale türünden ölçülmüştür. En düşük değer $(36.3 \mu \mathrm{m})$ A. akaka türünden elde edilmiş olup diğer dört tür ile aynı grup içerisinde yer aldıkları 
Çizelge 2' de görülmektedir. Stoma sayıları türlere göre değişiklik göstermekte olup en fazla $A$. kharputense türünde $1665.3 \mathrm{adet} / \mathrm{mm}^{2}$, en az stoma sayısı ise $A$. akaka türünde $663.3 \mathrm{adet} / \mathrm{mm}^{2}$ olarak belirlenmiştir.

Çizelge 2. Bazı Allium türlerinin stoma ve polen özelliklerine ait ortalama değerler ve oluşan gruplar

\begin{tabular}{|c|c|c|c|c|c|c|c|}
\hline Çeşit adı & $\begin{array}{l}\text { Stoma } \\
\text { çapı } \\
(\mu \mathrm{m})\end{array}$ & $\begin{array}{l}\text { Stoma } \\
\text { boyu } \\
(\mu \mathrm{m})\end{array}$ & $\begin{array}{l}\text { Stoma } \\
\text { say1s1 } \\
\left(\mathrm{mm}^{2} / \text { adet}\right)\end{array}$ & $\begin{array}{l}\text { Polen } \\
\text { çap1 } \\
(\mu \mathrm{m})\end{array}$ & $\begin{array}{l}\text { Polen } \\
\text { boyu } \\
(\mu \mathrm{m})\end{array}$ & $\begin{array}{l}\text { Polen } \\
\text { say1s1 } \\
(0.1 \\
\left.\mathrm{mm}^{2} / \text { adet }\right)\end{array}$ & $\begin{array}{l}\text { Polen } \\
\text { canlıl1k } \\
\text { oranı (\%) }\end{array}$ \\
\hline A. kharputense & $18.5 \mathrm{c}$ & $37.6 \mathrm{~b}$ & $1665.3 \mathrm{a}$ & $16.7 \mathrm{~b}$ & $29.9 \mathrm{~d}$ & $410.0 \mathrm{~d}$ & $67.8 \mathrm{~b}$ \\
\hline A. sintensii & $20.9 \mathrm{c}$ & $41.2 \mathrm{~b}$ & $979.3 \mathrm{~b}$ & $23.8 \mathrm{a}$ & $35.6 \mathrm{bc}$ & $595.1 \mathrm{~b}$ & $65.6 \mathrm{~b}$ \\
\hline A. giganteum & $19.2 \mathrm{c}$ & $38.6 \mathrm{~b}$ & $680.7 \mathrm{c}$ & $24.7 \mathrm{a}$ & $37.6 \mathrm{~b}$ & $735.5 \mathrm{a}$ & $85.1 \mathrm{a}$ \\
\hline A. akaka & $21.6 \mathrm{c}$ & $36.3 \mathrm{~b}$ & $663.3 \mathrm{c}$ & $26.8 \mathrm{a}$ & $41.5 \mathrm{a}$ & $191.4 \mathrm{e}$ & $51.0 \mathrm{c}$ \\
\hline A. vineale & $43.3 \mathrm{a}$ & $51.6 \mathrm{a}$ & 879.6b c & $23.7 \mathrm{a}$ & $33.8 \mathrm{c}$ & $185.4 \mathrm{e}$ & $47.8 \mathrm{c}$ \\
\hline $\begin{array}{l}\text { A. } \\
\text { scorodoprasum } \\
\text { subsp. rotundum }\end{array}$ & $33.9 \mathrm{~b}$ & $41.4 \mathrm{~b}$ & $726.2 \mathrm{c}$ & $25.1 \mathrm{a}$ & $32.5 \mathrm{~cd}$ & $484.5 \mathrm{c}$ & $70.5 \mathrm{~b}$ \\
\hline Ortalama & 26.3 & 41.1 & 923.4 & 23.4 & 35.2 & 433.7 & 64.6 \\
\hline F değeri & $77.72 * *$ & $13.89 * *$ & $32.46 * *$ & $12.67 * *$ & $14.81 * *$ & $79.33 * *$ & $27.06 * *$ \\
\hline LSD & 3.34 & 4.31 & 194.42 & 2.85 & 3.09 & 71.88 & 7.66 \\
\hline CV (\%) & 9.74 & 8.04 & 15.97 & 9.36 & 6.73 & 12.69 & 9.09 \\
\hline
\end{tabular}

** $\mathrm{p}<0.01$

Çizelge 2'de görüleceği gibi türlerin polen morfolojisi ve yoğunluğu farkl1lıklar göstermiştir. Yapılan ölçümlerde en yüksek polen eni $26.8 \mu \mathrm{m}$ ile $A$. akaka türünde tespit edilmiştir. Ancak, $A$. kharputense türü dışındaki diğer tüm Allium türleri ile aynı grup içerisinde yer almıştır. En düşük polen eni değeri ise $16.7 \mu \mathrm{m}$ ile $A$. kharputense türünde tespit edilmiştir. Çalışmada, en uzun polenler $41.5 \mu \mathrm{m}$ ile A. akaka türünde, en kısa polenler $29.9 \mu \mathrm{m}$ ile A. kharputense türünde tespit edilmiştir. Polen sayısı bakımından en fazla polen sayısı $735.5 \mathrm{adet} / \mathrm{mm}^{2}$ A giganteum türünden elde edilirken, en az polen sayısı değeri $185.4 \mathrm{adet} / \mathrm{mm}^{2}$ A. vineale türünde belirlenmiş ve $A$. akaka türü ile aynı grup içerisinde yer aldığ 1 görülmektedir (Çizelge 2). Polenlerde yapılan IKI canlılık testinde türlere göre en yüksek polen canlılık oranı \% 85.1 ile A. giganteum (\% 85.1) türünde elde edilmiştir. En düşük polen canlılığ 1 ise \% 47.8 ile A. vineale türünden elde edilirken $A$. akaka türü ile aynı grup içerisinde yer almıştır.

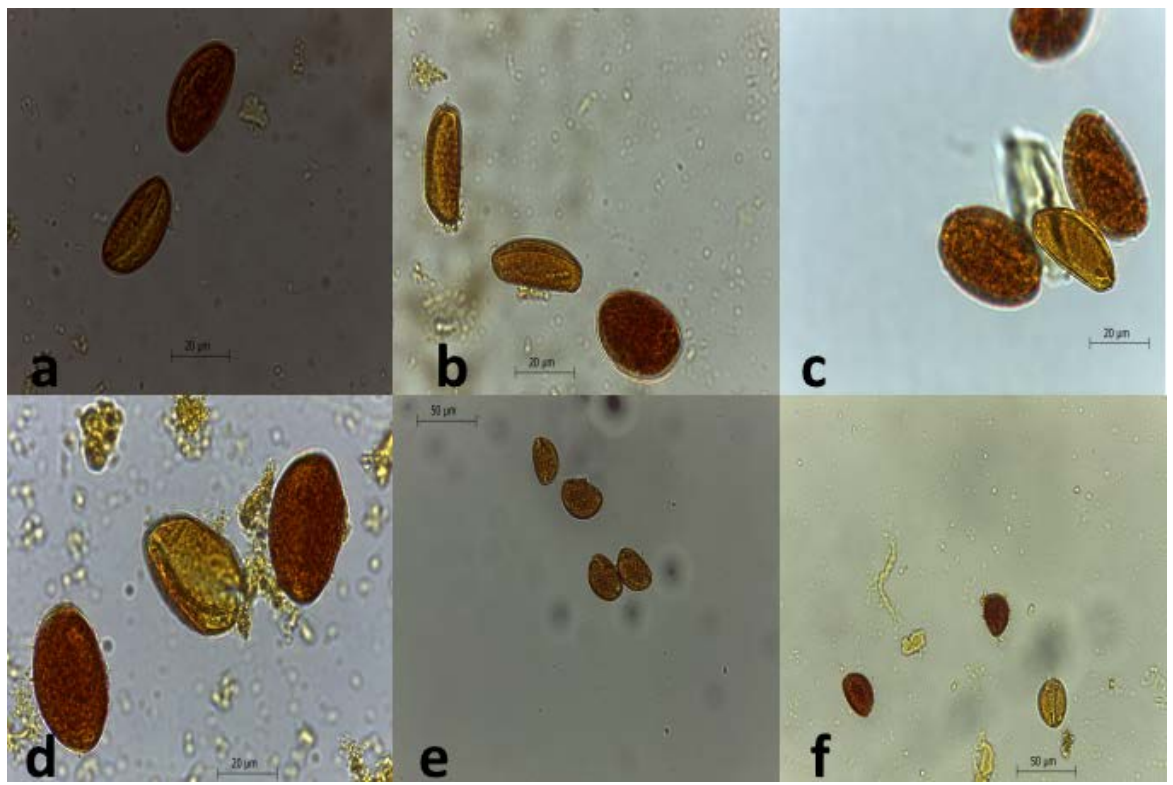

Şekil 2. Canlılık testi uygulanan polenlerin genel görünümü (Açık renkliler cansız, koyu renkliler canlı polenlerdir. a. A. kharputense, b. A. sintensii, c. A. giganteum, d. A. akaka, e. A. vineale, f. A. scorodoprasum subsp. rotundum). 


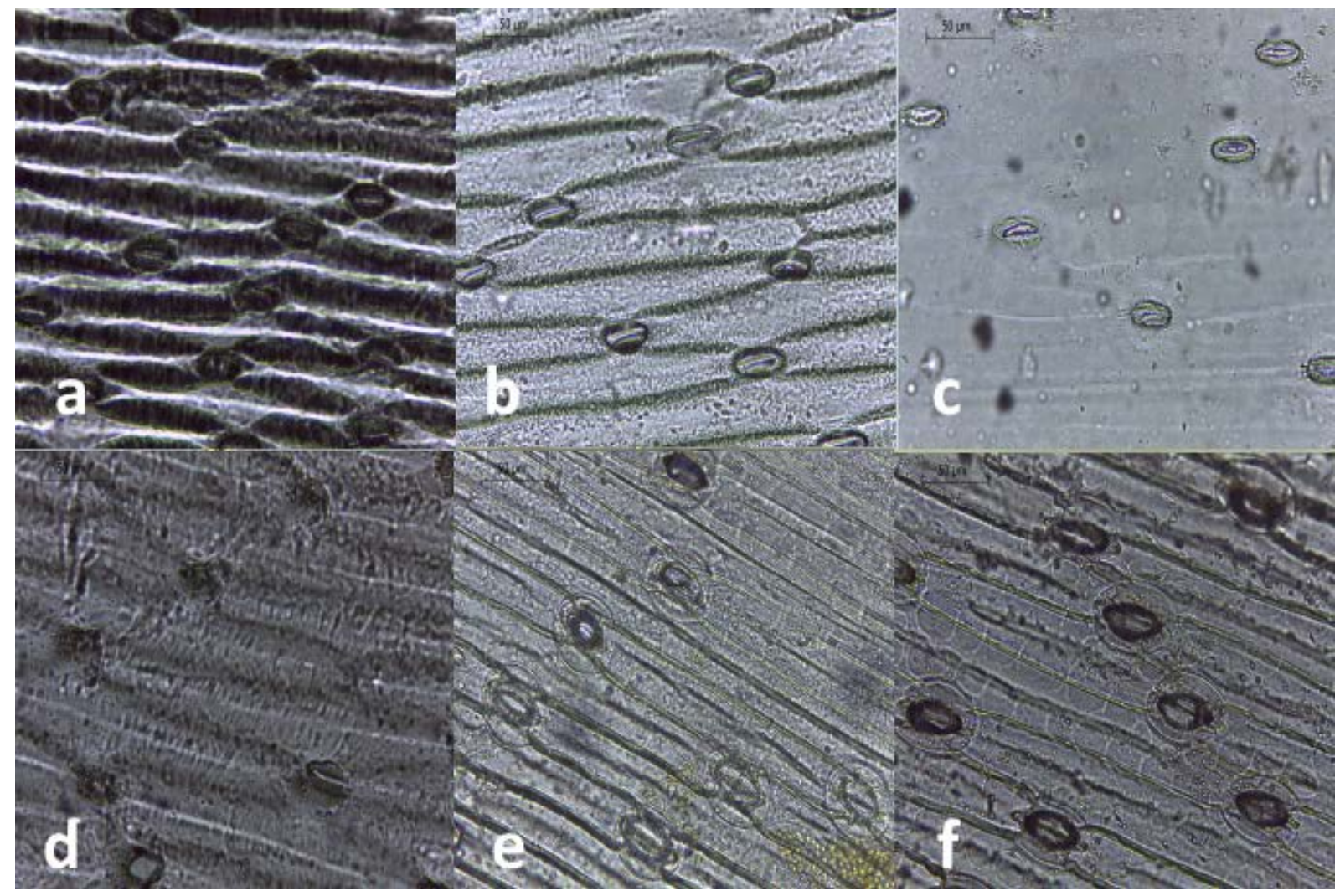

Şekil 3. Stomaların genel görünümü ( a. A. kharputense, b. A. sintensii, c. A. giganteum, d. A. akaka, e. A. vineale, f. A. scorodoprasum subsp. rotundum).

\section{Tartışma ve Sonuç}

Çok sayıda araştırmacı Allium türlerinin morfoloji ve anatomileri üzerine araştırmalar yapmış olup incelenen özelliklere ait ölçüm ve gözlemlerin türlere göre farklılıklar gösterdiğini belirtmişlerdir (Uysal, 1999; Pektaş, 2007; Özkur, 2009; Furat ve Genç, 2016). Guldigen ve Sensoy (2016), yaptıkları çalışmada sap uzunluğunu $A$. vineale ve $A$. scorodoprasum subsp. rotundum türlerinde $100 \mathrm{~cm}$ olarak belirtmişlerdir. Bu çalışmada yukarıda bahsi geçen aynı türlerde (A. vineale ve A. scorodoprasum subsp. rotundum) sap uzunluğu araştırıcıların sonuçlarına kıyasla daha düşük olmakla birlikte, diğer Allium türlerine bakıldığında en uzun bitki boyuna ve sap uzunluğuna sahip türler olarak ön plana çıkmışlardır. Tuncer ve ark. (2016), A. kharputense, A. scorodoprasum subsp. rotundum ve A. vineale türlerinde sırasıyla umbella çap $1(2.5-8.5,1-6,1.5-3 \mathrm{~cm})$, sap uzunluğu $(30-50,25-90,30-120 \mathrm{~cm})$, yaprak sayısı (2$3,2-5,3-4)$, yaprak genişliği (7-40, 8-15, 2-4 mm) ve pedisel uzunluğunu (1.5-2.4, 3.2-3.6, 0.8-2 cm) gibi özellikleri inceledikleri çalışmada elde ettikleri bulgular ile araştırma sonuçlarımız uyumludur. Yapılan geniş literatür taramasına göre şimdiye kadar yapılan çalışmalarda sınırlı sayıda Allium türü ele alınmıştır. Bu çalışmada daha önceden literatür bilgisine rastlanmayan Allium türleri de çalışmaya dahil edilerek bundan sonra yapılacak çalışmalara önemli bir kaynak oluşturulmaya çalışılmıştır.

Konu ile ilgili yapılan çalışmalarda, Yang ve ark. (2017), A. fistulosum L.'un stoma boyunu $51.59 \mu \mathrm{m}$, stoma enini $38.97 \mu \mathrm{m}$ ve stoma yoğunluğunu 55 adet olarak tespit ettiklerini bildirmişlerdir. Yapılan çalışmalarda; Allium türlerinde stoma yoğunluğunun kuraklıktan etkilendiği, miktarında düşüşlerin olduğu, aynı zamanda stoma yoğunluğundaki azalmaların kuraklık direncini artırabileceği ve fotosentetik kapasiteyi etkileyebileceği bildirilmiştir (Franks ve ark., 2015; Yang ve ark., 2017). Bazı araştırıcılar, stoma sayısı ve boyutlarının yaprağın alınma konumu(güneş/gölge), sulama, çevre koşulları ve gübreleme gibi uygulamalardan kaynaklı farklılık gösterdiğini belirtmişlerdir (Eriş ve Soylu, 1990, Marasalı ve Aktekin,2003, Uyak ve ark., 2015; Doğan ve ark., 2020). Pektaş (2007) yaptığı çalışmada stomaların adaptasyon açısından önemli olduğunu ve Allium türlerinde stoma boyutlarının farklılıklar gösterdiğini vurgulamıştır.

Kocakaya (2019) yaptığı çalışmada A. ampeloprosum türünde polen canlılık oranının \%52 - 86 arasında değiştiğini ve polen canlılığı ile tohum verimi arasında doğru bir orantı olduğunu bildirmiştir. 
Benzer şekilde Özhatay ve Koçyiğit (2009), 23 Allium türünde polen morfolojisini inceledikleri çalışmada türler arasında önemli farklılıklar olduğunu tespit etmişlerdir. Araştırıcılar polen ölçülerinin en düşük A. guttatum subsp. guttatum $(25.75 \times 19.22 \mu \mathrm{m})$ ve en yüksek A. roseum $(2.30 \times 51.19 \mu \mathrm{m})$ türünde olduğunu belirtmişlerdir. Bu çalışmada kullanılan türlerden olan A. scorodoprasum subsp. rotundum ( 34.8 x 31.15 - 21.75x $26.6 \mu \mathrm{m})$ ve A. vineale $(29.33$ x $33.35-20.3$ x $23.2 \mu \mathrm{m})$ türlerinin ölçüleri bahsi geçen çalışma ile paralellik göstermiştir. Polen yoğunluğunun ve canlılık oranının tohum bağlama açısından önemli bir parametre olduğu ve sslah çalışmalarında özellikle androgenesiste büyük önem taşıdığı araştırmacılar tarafından vurgulanmıştır (Kaska 2013; Kocakaya, 2019).

Anadolu, endemik türlerin de bulunduğu birçok Allium türüne ev sahipliği yapmaktadır. Türler doğal alanlarından bilinçsiz olarak toplanmakta ve hızlı bir şekilde risk kategorilerine girmektedir. Biyoçeşitliliğin korunması açısından Anadolu'da yaygın olarak kullanılan türlerin kültüre alınması büyük önem taşımaktadır. Yapılan çalışmada altı Allium türünün adaptasyon yeteneği belirlenmiş ve kültür ortamında üretilebileceği sonucuna varılmıştır. Polen miktarı ve canlılık oranları verim ile doğrudan ilintili karakterlerdir. Bu özellikler açısından ve stoma sayısı ile ebatlarında $A$. vineale ve $A$. scorodoprasum subsp. rotundum türlerinin ön plana çıktığı görülmüştür. Yapılan çalışma sonucunda ele alınan Allium türlerinin incelenen morfolojik özelliklerine göre $A$. scorodoprasum subsp. rotundum, $A$. vineale ile $A$. giganteum türlerinin ticari olarak üretilebileceği ve pazara sunulabileceği kanaatine varılmıştır. Bu çalışmada ele alınan Allium türlerinin yetiştiriciliğinin yapılması durumunda yöre halkı için alternatif bir gelir kaynağı olacağı ve türlerin doğadaki sürdürülebilirliğinin sağlanması açısından da oldukça önemli bir adım atılacağı görülmüştür.

\section{Kaynakça}

Doğan, A., Uyak, C., Akçay, A., Keskin, N., Gazioglu Şensoy, R., Çelik, F., Kunter, B., Çavuşoğlu, Ş., Özrenk, K. (2020). Hizan (Bitlis) Koşullarında Yetiştirilen Üzüm Çeşitlerinin Klorofil Miktarları ve Stoma Yoğunluklarının Belirlenmesi . Yüzüncü Yıl Üniversitesi Tarım Bilimleri Dergisi, 30 (4) , 652-665 . DOI: 10.29133/yyutbd.698508.

Ekşi, G., Özkan, A. M. G., \& Koyuncu, M. (2020). Garlic and onions: an eastern tale. Journal of Ethnopharmacology, 112675.

Eriş, A., \& Soylu, A. (1990). Stomatal density in various Turkish grape cultivars. Vitis, 382-389.

Eti, S. 1990. Çiçek tozu miktarını belirlemede kullanılan pratik bir yöntem. Çukurova Üniveristesi Ziraat Fakültesi Dergisi, 1990, 5(4), 49-58.

Fırat, M., \& Genç, İ. (2016). Türkiye'de doğal yayılış gösteren bazı soğan Allium L.-Amaryllidaceae türleri üzerine taksonomik notlar. Bağbahçe Bilim Dergisi, 3(3), 4-10.

Franks, P. J., W. Doheny-Adams, T., Britton-Harper, Z. J., \& Gray, J. E. (2015). Increasing water-use efficiency directly through genetic manipulation of stomatal density. New Phytologist, 207(1), 188-195.

Guldigen, O., \& Sensoy, S. (2015). Sirmo (Allium spp.), wild herb species used in herby cheese. VII International Symposium on Edible Alliaceae Niğde.

Kaska, A., Toprak, F. C., \& Alan, A. R. (2013). Gynogenesis induction in leek (Allium ampeloprasum L.) breeding materials. Current Opinion in Biotechnology, (24), S42.

Kaya, E. (2014). Türkiye Geofitleri Cilt 1. Atatürk Bahçe Kültürleri Araştırma Enstitüsü. Yayın No. 96, Yalova.

Kocakaya, V. (2019). Ginogenik pırasa (Allium ampeloprasum L.) hatlarının karakterizasyonu. (MSc), Pamukkale Üniversitesi, Fen Bilimleri Enstitüsü, Denizli, Türkiye.

Marasalı, B., \& Aktekin, A. (2003). Sulanan ve sulanmayan bağ koşullarında yetiştirilen üzüm çeşitlerinde stoma sayısının karşılaştırılması. Tarım Bilimleri Dergisi, 9 (3), 370-372.

Özhatay, N \& Koçyiğit, M. (2009). Pollen morphology of Allium species (Liliaceae) in European Turkey and around Istanbul. Phytologia Balcanica, 15 (2), 199 - 208, Sofia.

Özkur, F. N. (2009). Türkiye'de doğal olarak yetişen Allium cassium boiss., Allium isauricum hub.mor. ve Allium ertugrulii Demirelma ve Uysal.(Alliaceae) türleri üzerine anatomik, morfolojik ve palinolojik çalışmalar. (PhD), Selçuk Üniversitesi, Fen Bilimleri Enstitüsü, Konya, Türkiye..

Pektaş, A. (2007). Tuz Gölü (Cihanbeyli-Konya) Allium L.(Liliaceae) taksonlarının morfolojik, anatomik ve ekolojik özellikleri. (PhD), Selçuk Üniversitesi, Fen Bilimleri Enstitüsü, Konya, Türkiye. 
Poojary, M. M., Putnik, P., Kovačević, D. B., Barba, F. J., Lorenzo, J. M., Dias, D. A., \& Shpigelman, A. (2017). Stability and extraction of bioactive sulfur compounds from Allium genus processed by traditional and innovative technologies. Journal of Food Composition and Analysis, 61, 2839.

Putnik, P., Gabrić, D., Roohinejad, S., Barba, F. J., Granato, D., Mallikarjunan, K.\& Kovačević, D. B. (2019). An overview of organosulfur compounds from Allium spp.: From processing and preservation to evaluation of their bioavailability, antimicrobial, and anti-inflammatory properties. Food chemistry, 276, 680-691.

Rosello-Soto, E., Barba, F. J., Putnik, P., Bursac Kovacevic, D., Lorenzo, J. M., \& Cantavella-Ferrero, Y. (2018). Enhancing bioactive antioxidants' extraction from "Horchata de Chufa" by-products. Foods, 7(10),

Saljoughian, S., Roohinejad, S., Bekhit, A. E.-D. A., Greiner, R., Omidizadeh, A., Nikmaram, N., \& Mousavi Khaneghah, A. (2017). The effects of food essential oils on cardiovascular diseases: A review. Critical Reviews in Food Science and Nutrition, 1-18.

Tuncer, B., Firat, M., Yarali, F., \& Sarikamis, G. (2016). Morphology and utilization of Allium L. species used as herbs in cheese around Van province in Turkey. Acta Horticulturae, (1143), 171-178.

Tunçtürk, M., \& Tunçtürk, R. 2020. Van otlu peyniri ve yapımında kullanılan bitkiler ile ilgili genel bir değerlendirme. Ziraat Fakültesi Dergisi, 238-244.

Uyak, C., Keskin, N., Doğan, A., İlknur, R., Şensoy, G., \& Başdinç, M. A. (2015). Van ekolojisinde yetişen bazı üzüm çeşitlerinin stoma yoğunlukları ve klorofil miktarlarının belirlenmesi. VII. Ulusal Bahçe Bitkileri Kongresi(Özel sayı), Cilt II. Çanakkale..

Uysal, İ. (1999). Morphological, anatomical and ecological studies on the two Turkish endemic species collected from Kazdağı (B1 Balıkesir) Allium sibthorpianum Schultes \& Schultes Fill. And Allium reuterianum Boiss. Tr J of Botany, 23,137-148.

Yang, L., Liu, Q., Wang, Y., \& Liu, L. (2017). Identification and characterization of a glossy mutant in Welsh onion (Allium fistulosum L.). Scientia Horticulturae, 225, 122-127. 